\title{
Treatment of acute unilateral lung disease with differential lung intubation followed by asynchronous independent lung ventilation
}

\author{
Natan Weksler ${ }^{1}$, Miguel Iuchtman ${ }^{2}$, Anatol Stav ${ }^{3}$, and Leon Ovadia ${ }^{3}$ \\ ${ }^{1}$ Postsurgical Care Unit, Soroka Medical Center, Ben Gurion University of Negev, Beer Sheva 84101, Israel \\ ${ }^{2}$ Pediatric Surgery Unit, Department of Surgery A, Hillel Yaffe Medical Center, Hadera 38100, Israel \\ ${ }^{3}$ Department of Anesthesiology Hillel Yaffe Medical Center, Hadera 38100, Israel
}

Key words: Unilateral lung disease-Differential intubation-Ventilation

\section{Introduction}

For management of patients with unilateral lung disease independent lung ventilation is becoming popular since it can overcome most of the problems associated with conventional ventilation such as regional alveolar overdistention, increased ventilation-perfusion mismatching, venous admixture, and barotrauma [1-3]. Furthermore, applying selective positive end-expiratory pressure (PEEP) to the injured lung, one can selectively improve its volume at end expiration (i.e., its functional residual capacity) and to decrease the overall shunt fraction [4].

We had successfully applied asynchronous independent lung ventilation (AILV) in one patient with acute unilateral lung disease, in whom conventional ventilatory treatment methods failed to improve his clinical condition.

\section{Case report}

A 76-year-old man involved in a road accident was brought to the emergency room of the Hillel Yaffe Medical Center. On admission, he was disoriented, agitated and pale, tachypneic (30 breaths $\mathrm{min}^{-1}$ ), tachycardic $\left(125\right.$ beats $\left.\min ^{-1}\right)$ and with arterial blood pressure of $150 / 110 \mathrm{mmHg}$. The physical examination

Address correspondence to: N. Weksler

Received for publication on November 16, 1992; accepted on March 18, 1994 revealed decreased air entry over the left hemithorax and muffled heart sounds.

Endotracheal intubation was immediately performed, and a chest drain was inserted in the left hemithorax, anterior to the midclavicular line [5], releasing a large amount of air and a small quantity of blood. Two 16-gauge peripheral catheters were placed in the arm veins, and fluid replacement was promptly initiated.

The laboratory data were as follows: Hemoglobin $12 \mathrm{~g} \%$, Ht $38 \%$, WBC $9000 / \mathrm{mm}^{2}$. Glucose $170 \mathrm{mg} \%$, BUN $10 \mathrm{mg} \%, \quad \mathrm{Na}^{+} 140 \mathrm{mEq} \cdot \mathrm{l}^{-1}, \mathrm{~K}^{+} 6.2 \mathrm{mEq} \cdot \mathrm{l}^{-1}$. The arterial blood gases were: $\mathrm{pH}$ 7.15; $\mathrm{PaCO}_{2}$ $20 \mathrm{mmHg} ; \mathrm{PaO}_{2} 60 \mathrm{mmHg}\left(\mathrm{FIO}_{2}\right.$ 0.6); Bicarbonate $14 \mathrm{mEq} \cdot \mathrm{I}^{-1}$.

The diagnostic peritoneal lavage was positive, and a splenectomy was performed. During surgery, the estimated blood loss was about $2500 \mathrm{ml}$, and fluid replacement consisted of $4000 \mathrm{ml}$ of Hartman's solution and $1500 \mathrm{ml}$ of whole blood. The measured urinary output was $100 \mathrm{ml}$. At the end of surgery, the patient was transferred to the postanesthetic care unit, and connected to an MA 1 ventilator (Puritan Bennet, CA, USA) provided with an IMV low-resistance continuous-flow external device (IMV Assembly, Intersurgical, Middlesex, UK). He was hemodynamically stable, with the following laboratory results: $\mathrm{Hb} 8.7 \mathrm{~g} \%$, Ht $27 \%, \mathrm{Na}^{+}$ $133 \mathrm{mEl} \cdot 1^{-1}, \mathrm{~K}^{+} 5.2 \mathrm{mEq} \cdot \mathrm{l}^{-1}, \mathrm{Ca}^{++} 8 / 9 \mathrm{mg} \%$, BUN $7 \mathrm{mg} \%$, Creatinine $1 \mathrm{mg} \%$, pH 7.30, $\mathrm{PaCO}_{2} 30 \mathrm{mmHg}$, $\mathrm{PaO}_{2} 150 \mathrm{mmHg}\left(\mathrm{FIO}_{2} 0.4\right)$ and $\mathrm{HCO}_{3}^{-} 18 \mathrm{mEq} \cdot \mathrm{l}^{-1}$. The chest roentgenogram showed a chest drain in place and multiple fractures of ribs over the left hemithorax.

An epidural catheter was inserted at the T5/T6 level and plain $0.25 \%$ bupivacaine was continuously infused at a rate of $8 \mathrm{ml} / \mathrm{h}$ for postoperative analgesia [6]. Artificial ventilation was maintained for the next 4 days with a gradual reduction of the IMV frequency, and with achievement of spontaneous breathing and maintenance of good exchange parameters [oxygen saturation 
$\left(\mathrm{SaO}_{2}\right) \geq 90 \%$ at $\mathrm{FIo}_{2}$ of 0.21 with spontaneous breathing on $5 \mathrm{cmH}_{2} \mathrm{O}$ constant positive airway pressure (CPAP)] [7], was extubated and the chest drain was removed.

On the following day, he was transferred to the surgical ward, presenting acceptable blood gas results $(\mathrm{pH}$ 7.37, $\mathrm{PaCO}_{2} 37 \mathrm{mmHg}, \mathrm{PaO}_{2} 75 \mathrm{mmHg}$ at room air, $\mathrm{HCO}_{3}-21 \mathrm{mEq} \cdot \mathrm{l}^{-1}$ ) and good clinical parameters (quiet respiration with a rate of 22 breaths $\mathrm{min}^{-1}$ ).

Seventy-two $h$ later, he suddenly became agitated, extremely tachypneic ( 48 breaths $\mathrm{min}^{-1}$ ), with cyanosis and profuse sweating. Orotracheal intubation was immediately performed, and the patient was admitted to the respiratory care unit.

Controlled mechanical ventilation was started using the Erika Ventilator (Engstrom Medical, Bromma, Sweden), with a $\mathrm{FIO}_{2}$ of 1 . The registered compliance was then $10 \mathrm{ml} \cdot \mathrm{cmH}_{2} \mathrm{O}^{-1}$. On physical examination, no air entry was detected over the left hemithorax and the chest radiogram revealed massive collapse of the left lung (Fig. 1).

Under sedation with midazolam and muscular relaxation with atracurium, a 7-mm flexible fiberoptic bronchoscope was introduced through an adequate swivel connector (Portex, Kent, UK) adapted to the orotracheal tube to release the bronchial obstruction. However, a marked decrease in the pulse oxygen saturation from $96 \%$ to $80 \%$, despite administation of $100 \%$ oxygen, and frequent multifocal premature beats, led to interruption of the procedure. A new chest roentgenogram showed no improvement (Fig. 2).

The orotracheal tube was then changed by a left model double-lumen tube, inner diameter $5.4 \mathrm{~mm}$ each

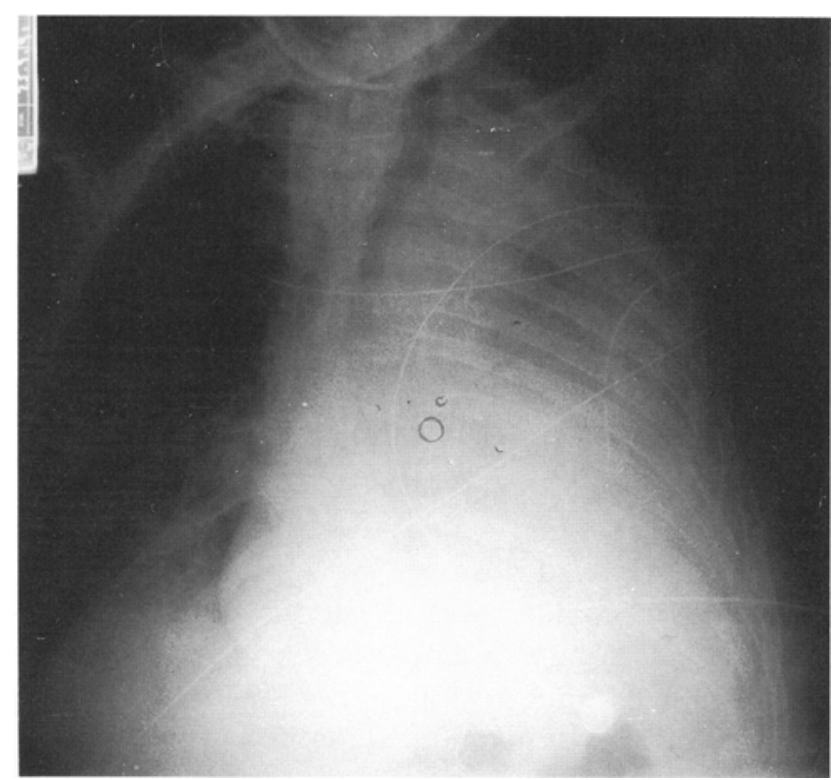

Fig. 1. Chest radiogram showing massive collapse of the left lung

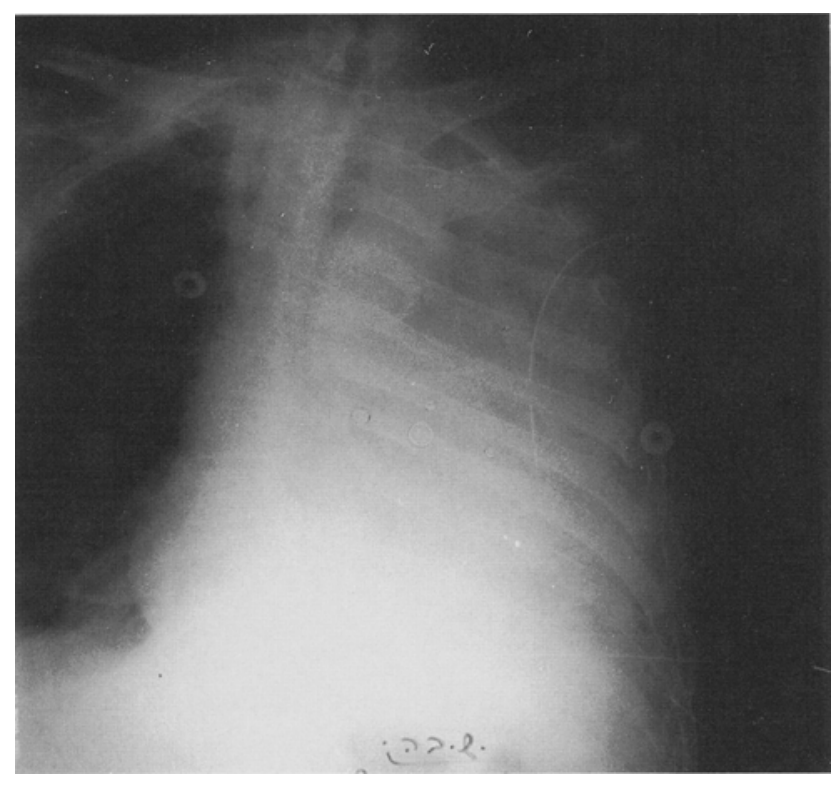

Fig. 2. No improvement after fiberoptic bronchoscopy

lumen, (Broncho-Cath, Mallinkrodt, Northampton, UK), and following assurance of adequate positioning of the tube, as proposed by Benumof and Alfery [8], the right lung was ventilated with $500 \mathrm{ml}$ tidal volume and a frequency of 14 breaths $\min ^{-1}$ with $5 \mathrm{cmH}_{2} \mathrm{O}$ positive end expiratory pressure. Through the left lumen, aggressive tracheobronchial toilette was instituted, with repeated infusion of $10 \mathrm{ml}$ of normal saline, selective suction and manual inflation of the left lung. During the procedure, the pulse oxymetry was $95 \%$, despite an $\mathrm{FIO}_{2}$ of 0.5 .

As soon as some air entry was detected over the left hemithorax, the left lung was connected to a second ventilator and ventilated with similar parameters to the contralateral lung, but with a positive end-expiratory pressure of $10 \mathrm{cmH}_{2} \mathrm{O}$.

The pulse oxygen saturation increased to $98 \%$ and the $\mathrm{FIO}_{2}$ was then decreased to 0.4 . The arterial blood gas results were as follow: $\mathrm{pH} 7.39 ; \mathrm{PaCO}_{2} 36 \mathrm{mmHg}$; $\mathrm{PaO}_{2} 160 \mathrm{mmHg}$; bicarbonate $20 \mathrm{mEq} \cdot \mathrm{l}^{-1}$.

Twenty-four $h$ later, the patient's condition allowed us to change the double-lumen tube to a regular one, and after a few hours, when breathing spontaneously through $5 \mathrm{cmH}_{2} \mathrm{O}$ at a $\mathrm{FIO}_{2}$ of 0.21 and a pulse oxygen saturation of $96 \%$, extubation was performed. The chest roentgenogram showed complete resolution of the atelectasis (Fig. 3).

\section{Discussion}

Mechanical ventilation with or without positive endexpiratory pressure is widely used in the treatment of 


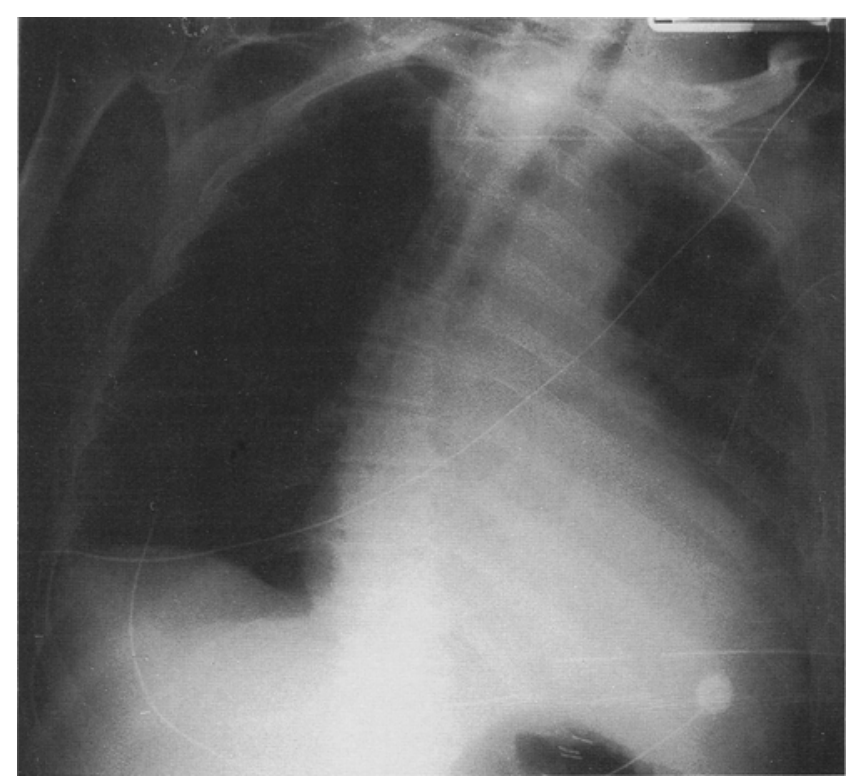

Fig. 3. Resolution of the atelectasis after Asynchronous Independent Lung Ventilation (AILV)

ventilatory failure. However, in the presence of unilateral lung disease with different lung compliances, the delivered tidal volume may diverge toward the more compliant lung, with consequent overdistention which increases the vascular resistance and shifts the blood flow to the stiffer lung [3]. Since the healthier lung is usually more compliant and the more affected lung is less so, the perfusion is forced away from the healthier to the sicker parenchyma. This may increase the ventilation-perfusion mismatching, leading to a decrease in arterial blood oxygenation [9].

Lung collapse following chest trauma is a frequent complication, even without evidence of bronchial occlusion [10]; this is related to the decreased alveolar tension as a consequence of decreased amounts of surfactant substance [11]. In addition, pain limits the patient's ability to cough effectively, which may lead to accumulation of tracheobronchial secretions, inducing bronchial plugging and atelectasis [12].

Conventional treatment of lung atelectasis involves adequate pain relief, antibiotics, physiotherapy and postural drainage [13].

Some authors have recommended the use of fiberoptic bronchoscopy for patients with massive symptomatic lung collapse, who lack central air bronchograms and fail to respond or tolerate $48 \mathrm{~h}$ of adequate respiratory physiotherapy [14]. However, fiberoptic bronchoscopy may induce airway trauma, cardiac arrhythmias, and may even worsen the arterial oxygenation [13].
In fact, we noted in our patient a profound hemoglobin desaturation, despite the administration of $100 \%$ oxygen, associated with multifocal premature ventricular contraction during fiberoptic bronchoscopy, which led to interruption of the procedure.

Independent lung intubation allowed selective bronchial lavage and suctioning releasing the obstructed bronchus, while oxygenation was preserved during the procedure. Moreover, further asynchronous independent lung ventilation maintained good aeration of the affected lung with good oxygenation, despite the decrease in the delivered oxygen concentration.

In conclusion, differential lung intubation followed by asynchronous independent lung ventilation represents a real improvement in the methodology of ventilatory therapy, and may be useful in dangerous hypoxic situations caused by unilateral lung disease when an adequate level of oxygenation is not achieved by conventional modes of ventilation.

\section{References}

1. Capan LM, Turndorf $\mathrm{H}$, Patel $\mathrm{C}$, Ramanathan S, Acinapura A, Chalon J (1980) Optimization of arterial oxygenation during onelung anesthesia. Anesth Analg 59:847-851

2. Kanarek DJ, Shanno DC (1975) Adverse effects of positive end expiratory pressure on pulmonary perfusion and arterial oxygenation. Am Rev Respir Dis 112:457-459

3. Crimi G, Candiani A, Conti G, Mattia C, Gasparetto A (1986) Clinical applications of independent lung ventilation with unilateral high-frequency jet ventilation (ILV-UHFJV). Intensive Care Med 12:90-94

4. Benumof JL (1982) One lung ventilation: Which lung should be PEEPed. Anesthesiology 56:161-163

5. Advanced Trauma Life Support Course (1988) Committee of Trauma. American College of Surgeons, pp 101-102

6. Bourvine A, Shemesh YI, Joffe B, Barzilay E (1991) Treatment of flail chest. Harefuah, J Israel Med Assoc 121:302-305

7. DeHaven CB, Hurst JM, Branson RD (1986) Evaluation of two different extubation criteria: Attributes contributing to success. Critical Care Med 14:92-9

8. Benumof JL, Alfery DD (1986) Anesthesia for thoracic surgery. In: Miller RD (ed) Anesthesia. New York, Churchill Livingstone, pp 1400-1402

9. Kvetan V, Carlon GC, Howland WS (1982) Acute pulmonary failure in asymetric lung disease: Approach to management. Crit Care Med 10:114-118

10. Murray JF (1985) Treatment of acute total atelectasis. Use of a double lumen tube. Anaesthesia 40:158-162

11. Petty TL, Fowller AA (1983) Another look at ARDS. Intensive Crit Care Dig 2:10-14

12. Miller HAB, Taylor GA, Harrison AW, Maggisano R, Hanna S, De Lacy JL, Shulman H (1983) Management of flail chest. Can Med Assoc J 129:1104-1107

13. Mackenzie CF, Shin B (1985) Cardiorespiratory function before and after chest physiotherapy in mechanically ventilated patients with post-traumatic respiratory failure. Crit Care Med 13: $483-6$

14. Marini JJ (1989) Critical care medicine-The essentials, 1st edn. Williams and Wilkins, Baltimore, pp 177-178 